International Journal of Physical Research, 8 (2) (2020) 50-54
International Journal of Physical Research
SPC
Website: $w$ ww.sciencepubco.com/index.php/IJPR
Research paper

\title{
Alpha activity emitted from leaves and roots of beetroot plant planted in enhanced soil with fertilizers
}

\author{
Sahar Ahmed Amin * \\ Environmental Research Center, University of Technology- Iraq \\ *Corresponding author E-mail: 11482@uotechnology.edu.iq
}

\begin{abstract}
This study is to assesses radioactive materials transported to the beetroot plants grow in different fertilized soil. Equivalent weights of fertilizers were added to the soil prior the plantation. The alpha track densities were estimated utilizing solid state nuclear track detector (SSNTDs), CR-39. The obtained results show that alpha track densities in Beetroot plants in the lower and upper sides of plant leaves were varied from $67.62 \mathrm{Tr} . \mathrm{cm}-2$ to $101.83 \mathrm{Tr} . \mathrm{cm}-2$ and from $45.35 \mathrm{Tr} . \mathrm{cm}-2$ to $94.67 \mathrm{Tr} . \mathrm{cm}-2$ with mean values of $89.96 \mathrm{Tr} . \mathrm{cm}-2$ and 68.48 Tr.cm-2, respectively. Alpha track densities were also measured in the samples of the enhanced plantation soil with fertilizers and in the whole parts of the Beetroot plant which were planted in these soils. These values were compared with alpha track densities obtained from fertilizer samples in the previous studies. The lower face of leaves gives higher $\alpha$-particles activity than that obtained from the upper face. As well as, the alpha activity from the plants planted in soils enhanced with phosphate compost was found greater as contrast with that planted in a soil enhanced with organic fertilizer. The utilization of organic fertilizer don't cause much risks like contrasted with phosphate fertilizers. Therefore, the alpha activity depends on the nature of fertilizers added to the soil.
\end{abstract}

Keywords: Fertilizers; Beetroot Plant; Radioactivity; Soil; SSNTDs.

\section{Introduction}

Naturally occurring radiation is created as a result of unstable nuclei present in the earth's crust or from the atmosphere [1]. Under specific conditions, natural radioactive substances can be considered as dangerous radiological hazards. Thus, assessment of the radiation dose to population is important in order to identify the risks that affect human health and to beware of any future variations in the ecological radioactive materials and its effect on human activities [2].

Radioactivity is everywhere around us in the soil, air, water and plants which they have determinable quantity of radioactive materials. Metabolism process of plant organisms and physiochemical characteristics of the soil may cause accumulation of radio-isotopes in their organism species. Thus, this will in turn increase risk to humans through food chain. Radionuclides in the fertilizers are transferred to the plant when they applied to them [3]. Fertilizers are fundamental in the plant's nutrition. They contain many elements in addition to radioactive nuclei with their decay products. Phosphate fertilizers are considered as technologically enhanced natural radiation, which increases the environmental uranium and partially thorium concentrations in the environment [4]. Markose [5], Jibiri et al. [6] and many other researchers have studied the presence of radioactivity in plant organs. Humans are exposed to soil contamination through food chain (soilplant-human) pathway and incidental soil ingestion (soil-human) pathway.

The predictable amount of radionuclides that get in a plant from soil is termed by soil-plant concentration ratio [7].

The investigation of natural radioactivity in plants and related radiation exposure through the particular nourishment materials is a significant consideration.

Microorganisms are naturally accompanying with plant roots which can directly or indirectly affect the movement, availability and acquirement of elements in the plants [8]. The usage of fertilizers in soil cause radiological effect due to lung internal irradiation by $\alpha$ particles, radon and thoron progenies and the external irradiation of the body by gamma rays emitted from the radionuclides. Radon is harmful to humans and it makes the major natural radiation exposure to human being [9-11].

In the present work, alpha activity has been estimated in leaves of beetroot plants grown using different types of fertilizers like MAP (Monoammonium Phosphate), TSP (Triple Super Phosphate), NPK (nitrogen, phosphate and potassium), $\mathrm{P}_{2} \mathrm{O}_{5}$ (Phosphorus pentoxide), cryolite, zeolite, and organic fertilizer. The fertilizers have been added with the same amount before plantation.

The present study is important not only for the determination of levels of harmful pollutants discharged to the environment but also to assess how much living creatures gain due to food digestion. It is also important to understand the behavior of natural radionuclides in the environment, because such information can be used as the associated parameter values for the radiological assessments [12]. On the other hand, such information can be used as an important data in order to establish baseline data for the future radiation impact assessment, radiation protection and exploration [13]. 


\section{Materials and methods}

CR-39 track detector was used to measure the activity of alpha particles in beetroot plant. Beetroot seeds were planted in planting pots containing equal amount of sandy soil $(10 \mathrm{~kg})$. Nine types of fertilizers amount of $20 \mathrm{~g}$ were added in each pot and one control pot with no additives. The added fertilizers were MAP, Cryolite, TSP, Zeolite, NPK, $\mathrm{P}_{2} \mathrm{O}_{5}$ and organic fertilizer. The seeds were planted at depth 2 to $3 \mathrm{~cm}$ from the soil surface. All pots were left outside at same environmental conditions and they were watered at regular period of time. When the plants grown up, three types of exposure have been made:

- Leaves from each sample were picked, washed with tap water to remove any contamination. After washing the leaves left to dry in normal room condition until they completely dry. Then each leaf sample was put between two pieces of CR-39 SSNTD's (size 3x3 $\mathrm{cm}^{2}$ ), covered by aluminum foil sheet and kept into closed plastic containers to isolate the samples from the environment [14, 15].

- Whole parts of each plant samples were dried, crushed and sieved and a weight of $30 \mathrm{~g}$ of each were put in the bottom of a sealed container with a piece of CR-39 $\left(1.5 \times 1.5 \mathrm{~cm}^{2}\right)$ sticked in the inner side of the cover of the cup.

- A weight of $30 \mathrm{~g}$ of dry soil collected from each pot were put in the bottom of a sealed container with a piece of CR-39 (1.5 x 1.5 $\mathrm{cm}^{2}$ ) sticked in the inner side of the cover of the cup.

After 60 days of exposure time, the pieces of CR-39 detectors were taken out and etched in $6.25 \mathrm{~N}$ of Sodium hydroxide solutions at $70{ }^{\circ} \mathrm{C}$ for 4 hrs. Then, by using optical microscope, $\alpha$-tracks per unit area were counted.

\section{Results and discussion}

\subsection{Alpha activity from beetroot plant leaves}

Alpha track activities for the beetroot plant leaves planted in different fertilized soils were measured and the results are given in Table 1 . The obtained results show that $\alpha$-track activity of the lower and upper faces of the Beetroot leaves varied from $74.78 \mathrm{Tr} . \mathrm{cm}^{-2}$ to 101.83 Tr.cm ${ }^{-2}$ and $46.94 \mathrm{Tr} . \mathrm{cm}^{-2}$ to $94.67 \mathrm{Tr} . \mathrm{cm}^{-2}$ with mean values of $93.61 \mathrm{Tr} . \mathrm{cm}^{-2}$ and $70.01 \mathrm{Tr}^{-\mathrm{cm}^{-2}}$ respectively. The mean values of total $\alpha-$ track density and $\alpha$-track density per day for both faces were $81.81 \mathrm{Tr} . \mathrm{cm}^{-2}$ and $1.36 \mathrm{Tr} . \mathrm{cm}^{-2} . \mathrm{d}^{-1}$, respectively. The activities of $\alpha$-track for the lower and upper faces of the beetroot plant sample grown in soil without fertilizers were $67.72 \mathrm{Tr} . \mathrm{cm}^{-2}$ and 45.35 Tr.cm ${ }^{-2}$ respectively with mean value of $56.49 \mathrm{Tr} . \mathrm{cm}^{-2}$. The mean value of alpha track density/day was $1.36 \mathrm{Tr} . \mathrm{cm}^{-2} . \mathrm{d}^{-1}$.

Table 1: Total Alpha Track Activities Measured in the Beetroot Plant's Leaves

\begin{tabular}{|c|c|c|c|c|}
\hline \multirow{2}{*}{ Fertilizer } & \multicolumn{3}{|c|}{ Alpha track density $\left(\mathrm{Tr} . \mathrm{cm}^{-2}\right)$} & \multirow{2}{*}{$\begin{array}{l}\text { Alpha track density/day }\left(\operatorname{Tr} . \mathrm{cm}^{-2} \cdot \mathrm{d}^{-1}\right) \\
\text { Mean }\end{array}$} \\
\hline & Lower side & Upper side & Mean & \\
\hline Cryolite & 100.24 & 46.94 & 73.59 & 1.23 \\
\hline NPK1 & 90.69 & 90.69 & 90.69 & 1.51 \\
\hline $\mathrm{P} 2 \mathrm{O} 5$ & 101.03 & 89.10 & 95.07 & 1.58 \\
\hline Zeolite & 98.65 & 68.42 & 83.53 & 1.39 \\
\hline TSP1 & 95.47 & 77.96 & 86.71 & 1.45 \\
\hline TSP2 & 80.35 & 68.42 & 74.38 & 1.24 \\
\hline MAP1 & 101.83 & 51.71 & 76.77 & 1.28 \\
\hline MAP2 & 99.44 & 94.67 & 97.06 & 1.62 \\
\hline Organic & 74.78 & 48.53 & 61.65 & 1.03 \\
\hline Without & 67.62 & 45.35 & 56.49 & 0.94 \\
\hline Min & 74.78 & 46.94 & 61.65 & 1.03 \\
\hline Max & 101.83 & 94.67 & 97.06 & 1.62 \\
\hline Mean & 93.61 & 70.01 & 81.81 & 1.36 \\
\hline
\end{tabular}

\subsection{Alpha activity from the whole plant and Soil}

Radon concentrations for whole plants and soil samples enhanced with different types of fertilizers are presented in Table 2 and Fig. 1. The lowest radon concentration found in soil samples enhanced with organic fertilizer with value of $604.61 \mathrm{Tr} / \mathrm{cm}^{-2}$ while the soil sample enhanced with MAP fertilizer gives the highest radon concentration with value of $1050.11 \mathrm{Tr} / \mathrm{cm}^{-2}$. Whereas, the obtained results show that radon concentration in the beetroot plant grows in soil enhanced with organic fertilizer is the highest with value of $604.61 \mathrm{Tr} / \mathrm{cm}^{-2}$ while the lowest value was $310.26 \mathrm{Tr} / \mathrm{cm}^{-2}$ in the beetroot plant grows in the soil enhanced with NPK2 fertilizer.

Table 2: Alpha Track Density in Soil and Beetroot Plant Samples

\begin{tabular}{llll}
\hline Sample & Fertilizer (25) & Soil & Beetroot Plant \\
\hline Cryolite & 6125.70 & 883.05 & 477.33 \\
NPK & 5171.04 & 747.81 & 389.82 \\
P2O5 & 8074.78 & 946.70 & 517.10 \\
Zeolite & 7159.90 & 891.01 & 501.19 \\
TSP1 & 3699.28 & 636.44 & 389.82 \\
TSP2 & 5608.59 & 835.32 & 445.51 \\
MAP1 & 17859.98 & 1050.12 & 604.61 \\
MAP2 & 12211.61 & 986.48 & 580.75 \\
Organic & 2505.97 & 604.61 & 326.17 \\
Without & ------ & 580.75 & 310.26 \\
\hline
\end{tabular}




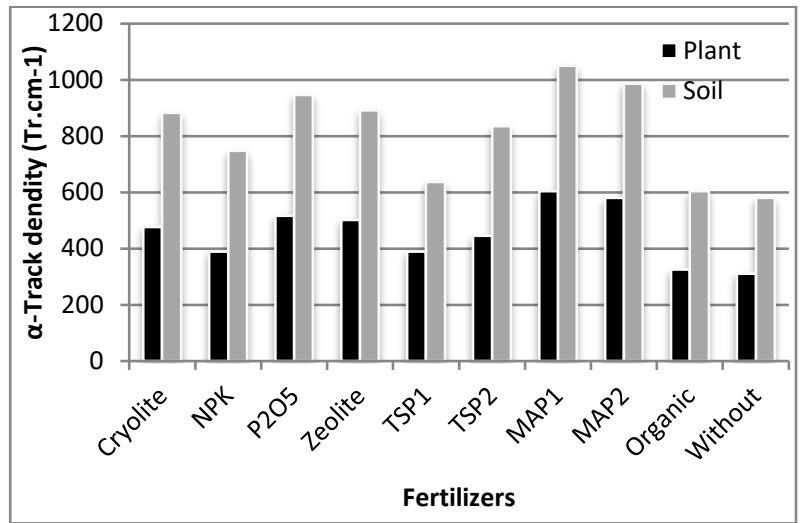

Fig. 1: Alpha Track Density for Soil and Plant Samples Enhanced with Different Types of Fertilizers.

The variation in alpha track density per day $\left(\mathrm{Tr}_{\mathrm{cm}} \mathrm{cm}^{-2} \cdot \mathrm{d}^{-1}\right)$ for different fertilized soil and for Beetroot plant planted in different fertilized soil compared with plain soil (not fertilized) are shown in Fig. 2. As well as, track density per day for the fertilizer samples [16] is also added in Fig. 2.

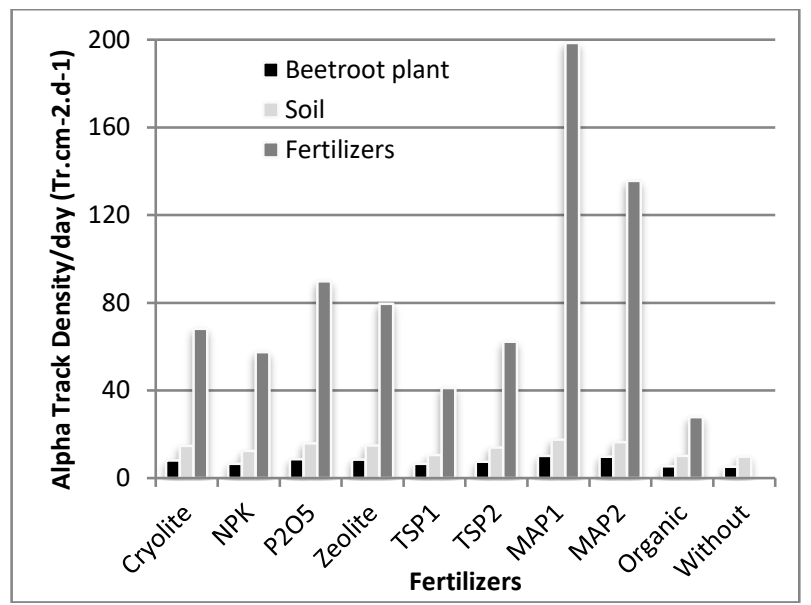

Fig. 2: Alpha Track Densities Per Day for Soil and Plant Samples Enhanced with Different Types of Fertilizers in Comparison with That of Fertilizers.

The plants that planted in fertilized soils gives higher activities than that planted in unfertilized soil. Alpha track activities from leaves of beetroot plant samples planted in the soils with addition of fertilizer were higher than that measured in the plant samples grown in organic soil. This might be ascribed to reality that the radioactive material (uranium and radium) concentrations in the soil were upgraded due to the addition of the phosphate fertilizers, where many scientists reported that high radioactive materials were content in such phosphate fertilizers $[17,18]$. These radionuclides exchange from soil to plant alongside fundamental supplements and amass in different parts of the plants. The quantity of alpha tracks generated on CR-39 detector are specifically corresponding to radioactive materials exist in leaves, in this way with utilization of various fertilizers, the radioactive materials are increased in the plant as presented in the present work. Figs. 3 $\& 4$ illustrate the alpha track density and alpha track density per day for both faces of beetroot plant leaves planted with different fertilizers.

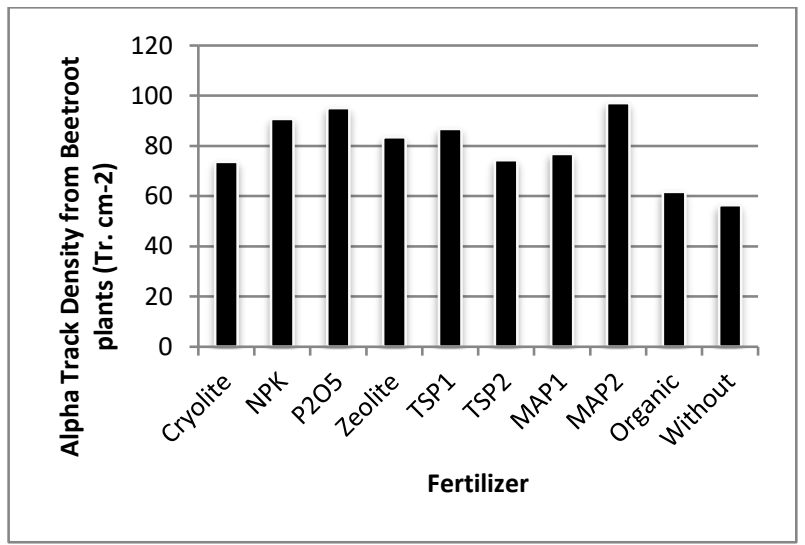

Fig. 3: Mean Values of A-Track Activity from Beetroot Leaves Planted in Soils Enhanced with Various Fertilizers Compared with ${ }^{-}$That Planted in Row Soil. 


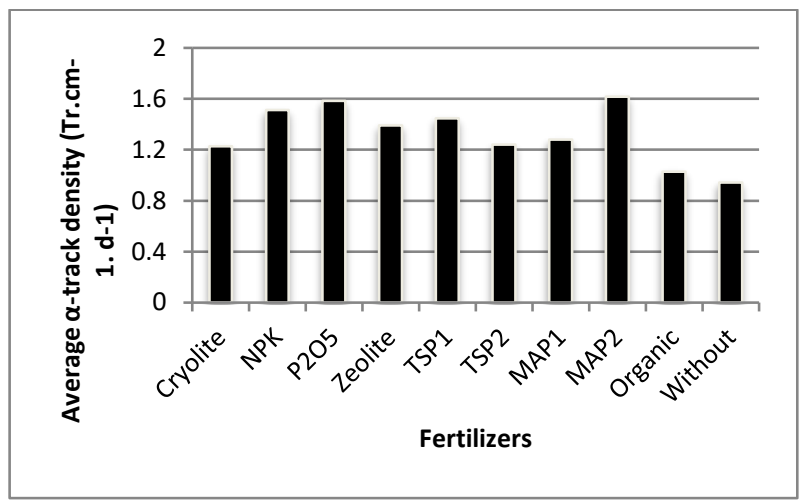

Fig. 4: Mean Values of A-Track Activity/Day from Beetroot Leaves Planted in Soils Enhanced with Various Fertilizers Compared with That Planted in Row Soil.

Organic fertilizer show the lowest $\alpha$-track density per day with values of $5.44 \mathrm{Tr} . \mathrm{cm}^{-2} \cdot \mathrm{d}^{-1}$ and $10.08 \mathrm{Tr} . \mathrm{cm}^{-2} \cdot \mathrm{d}^{-1}$, While MAP1 fertilizer gives the highest $\alpha$-track density per day with values of $10.61 \mathrm{Tr} . \mathrm{cm}^{-2} \cdot \mathrm{d}^{-1}$ and $17.50 \mathrm{Tr} . \mathrm{cm}^{-2} \cdot \mathrm{d}^{-1}$ for beetroot plant and soil samples respectively. A positive correlation between $\alpha$-track density obtained from soil and that's obtained Beetroot plants is shown in Fig. 5.

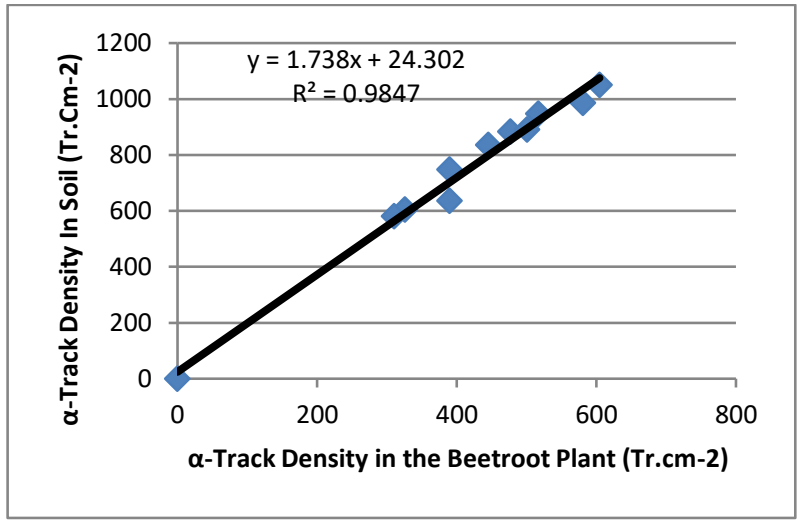

Fig. 5: Correlation of A-Track Densities between Alpha Track Density of Soil and Beetroot Plant Samples.

\section{Conclusions}

The utilization of natural and phosphate manures to build the yield creation is a typical practice in a large portion of the nations. The utilization of fertilized soil is the reason of the increment in exchange of radioactive materials from the soil to different parts of the plant. The activity of $\alpha$-particles is found higher from the lower face of leaves than that from the upper face. This might be ascribed that the trichrome thickness at lower side of the leaves is greater than the upper side of the leaves.

The alpha activity from the plants planted in soils enhanced with phosphate compost was found greater as contrast with that planted in a soil enhanced with organic fertilizer. This might be ascribed to reality that the phosphate fertilizers contain higher concentrations of radioactive materials (radium and thorium). The utilization of organic fertilizer don't cause much risks like contrasted with phosphate fertilizers. This may have been brought about by the existence of uranium and radium in the phosphate rocks; crude materials utilized for the compost's generation.

Therefore, the alpha activity depends on the nature of fertilizers added to the soil. This might be because of the variety of level in radio nuclides in the fertilizers utilized for the plants growth.

\section{Acknowledgment}

I would like to express my special thanks to Environmental Research Center for providing me with all facilities that were required in completing this project. As well as, I would like to thank all my colleagues in the Center for sharing their experience and for their support.

\section{References}

[1] S. Hazrati, A.N. Baghi, H. Sadeghi, M. Barak, S. Zivari, S. Rahimzadeh, Investigation of natural effective gamma dose rates case study: Ardebil Province in Iran, Iranian Journal of Environmental Health Science \& Engineering 9(1) (2012). https://doi.org/10.1186/1735-2746-9-1.

[2] R. Mehra, S. Kumar, R. Sonkawade, N.P. Singh, K. Badhan, Analysis of terrestrial naturally occurring radionuclides in soil samples from areas of Sirsa district of Haryana, India using gamma ray spectrometry, Environmental Earth Science 59 (2010) 1159-1164. https://doi.org/10.1007/s12665009-0108-3.

[3] M. C. Okeji, K.K. Agwu, F.U. Idigo, Assessment of natural radioactivity in phosphate ore, phosphogypsum and soil samples around a phosphate fertilizer plant in Nigeria, Bulletin of Environmental Contamination and Toxicology 89 (2012) 1078-1081. https://doi.org/10.1007/s00128-012$0811-8$.

[4] D. Ghosh, A. Deb, S. Bera, R. Sengupta, K.K. Patra (2008) Measurement of natural radioactivity in chemical fertilizer and agricultural soil: evidence of high alpha activity, Environmental Geochemistry \& Health 30(1) (2008) 79. https://doi.org/10.1007/s10653-007-9114-0.

[5] P.M. Markose, Studies on the Environmental Bahaviour of Radium from Uranium Mill Tailings. PhD thesis, University of Mumbai (1990). https://doi.org/10.1007/s10653-007-9114-0. 
[6] N.N. Jibiri, I.P. Farai, S.K. Alausa, Activity concentration of ${ }^{226}$ Ra, ${ }^{232} \mathrm{Th}$ and ${ }^{40} \mathrm{~K}$ in different food crops from a high background radiation area in Bitsichi, Jos Plateau, Nigeria, Radiation and Environmental Biophysics 46 (2007) 53-59. https://doi.org/10.1007/s00411-006-0085-9.

[7] S.B. Chen, Y.G. Zhu, Q.H. Hue, Soil to plant transfer of ${ }^{238} \mathrm{U},{ }^{226} \mathrm{Ra}$ and ${ }^{232} \mathrm{Th}$ on a uranium mining-impacted soil from southeastern China, Journal Environmental Radioactivity 82 (2005) 223-236. https://doi.org/10.1016/j.jenvrad.2005.01.009.

[8] D.S. Robinson, Food biochemistry and nutritional value, New York, USA: Longman scientific and technical publisher (1990).

[9] G. Ielsch, D. Thieblemont, V. Labed, P. Prichon, G. Tymen, C. Ferry, M. C. Robe, J. C. Baubron, F. Bechennec, Radon ( ${ }^{222}$ Rn) level variations on a regional scale influence of the basement trace element $(\mathrm{U}, \mathrm{Th})$ geochemistry on radon exhalations rates, Journal of Environmental Radioactivity 53 (2001) 75-90. https://doi.org/10.1016/S0265-931X(00)00106-5.

[10] D.K. Sharma, A. Kumar, M. Kumar, S. Singh, Study of uranium, radium and radon exhalation rate in soil samples from some areas of Kangra district, Himachal Pradesh, India using solid-state nuclear track detectors, Radiation Measurements 36 (2003) 363-366. https://doi.org/10.1016/S13504487(03)00152-5.

[11] J. Wiegand, A guideline for the evaluation of the soil radon potential based on geogenic and anthropogenic parameters, Environmental Geology 40 (2001) 949-963. https://doi.org/10.1007/s002540100287.

[12] S.R. Chakraborty, R. Azim, A. K. M. Rezaur Rahman, R. Sarker, Radioactivity concentrations in soil and transfer factors of radionuclides from soil to grass and plants in the Chittagong city of Bangladesh, Journal of Physical Science 24(1) (2013) 95-113.

[13] A.T. Ramli, A. Wahab, M.A. Hussein, W.A. Khalik, Environmental ${ }^{238} \mathrm{U}$ and ${ }^{232}$ nd concentration measurements in an area of high-level natural background radiation at Palong, Johor, Malaysia, Journal of Environmental Radioactivity 80 (2005) 287-304. https://doi.org/10.1016/j.jenvrad.2004.06.008.

[14] P. Chauhan, R.P. Chauhan, Measurement of fertilizers induced radioactivity in tobacco plants and elemental analysis using ICAP-AES, Radiation Measurements 63 (2014a) 6-11. https://doi.org/10.1016/j.radmeas.2014.02.006.

[15] P. Chauhan, R.P. Chauhan, Variation in alpha radioactivity of plants with the use of different fertilizers and radon measurement in fertilized soil samples. Journal of Environmental Health Science \& Engineering 12 (2014b) 70. https://doi.org/10.1186/2052-336X-12-70.

[16] S.M.D. Al-Nuzal, S.A. Amin, M.H.M. Lami, B.H. Jazaa, Natural Radioactivity Level of Phosphate Fertilizers and Related Products from Al-Qaim Complex Plant in Iraq by Using Solid State Nuclear Track Detector, Engineering \& Technology Journal 34(B3) (2016) 394-404.

[17] N. Khalifa, A.G.M. El-Arabi, Natural radioactivity in farm soil and phosphate fertilizer and its environmental implications in Qena governorate, Upper Egypt, Journal of Environmental Radioactivity 84 (2005) 51-64. https://doi.org/10.1016/j.jenvrad.2005.04.007.

[18] P. Chauhan, R.P. Chauhan, M. Gupta, Estimation of naturally occurring radionuclides in fertilizers using gamma spectrometry and elemental analysis by XRF and XRD techniques. Microchemical Journal 106 (2013) 73-78. https://doi.org/10.1016/j.microc.2012.05.007. 